\title{
Тесемочное окутывание восходящей аорты при ее постстенотическом расширении и коррекции аортального стеноза
}

\author{
Попов В. В., Большак А. А., Списаренко С.П., Малышева Т.А., Лазоришинец В. В.
} ГУ «Национальный институт сердечно-сосудистой хирургии имени Н. М. Амосова НАМН» (Киев)

\begin{abstract}
Цель работы - изучить клинические возможности оригинальной методики хирургической коррекции постстенотических аневризм восходящей аорты (ВА) при коррекции аортального стеноза.

В отделе хирургического лечения приобретенных пороков сердца Института с 01 января 2005 г. до 01 января 2017 г. по поводу аортального порока с преобладанием стеноза в сочетании с постстенотическим расширением восходящей аорты произведено протезирование аортального клапана (ПАК) в сочетании с тесемочным окутыванием восходящей аорты у 174 пациентов. Госпитальная летальность составила $0,6 \%$.

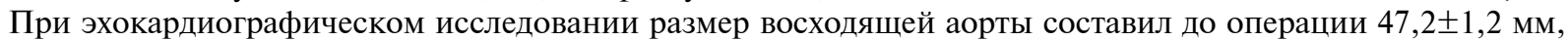

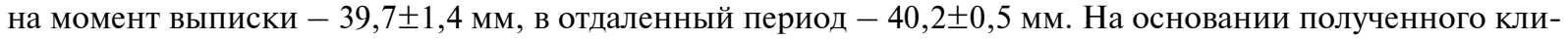
нического опыта представляется целесообразным рекомендовать оригинальную методику тесемочного окутывания восходящей аорты от основания некоронарного синуса при ее расширении (40 мм и более) в сочетании с ПАК при постстенотическом расширении ВА.
\end{abstract}

Ключевые слова: расширение восходящей аорты, резекция ВА, окутывание восходящей аорты, искусственное кровообращение.

Применение сосудистого протеза при замене пораженного участка восходящей аорты (ВА) сопряжено с риском повышенной летальности, а в отдаленный период - с инфицированием протеза и риском несостоятельности анастомозов. Как альтернативу этому осложнению при малых размерах аневризмы восходящей аорты доктор Робичек в 1976 году предложил методику экзопротезирования ВА сосудистым протезом. В развитие этого направления нами 10 лет назад предложена методика тесемочного экзопротезирования ВА. Изучению результатов этой работы посвящена данная статья.

Цель работы - изучить клинические возможности применения оригинальной методики хирургической коррекции постстенотических аневризм восходящей аорты при коррекции аортального стеноза.

Материалы и методы. В отделе хирургического лечения приобретенных пороков сердца Института с 01 января 2005 г. до 01 января 2017 г. по поводу аортального порока с преобладанием стеноза в сочетании с постстенотическим расширением восходящей аорты произведено протезирование аортального клапана (ПАК) в сочетании с комплексным тесемочным окутыванием восходящей аорты у 174 пациентов. Мужчин было 105 $(60,3 \%)$, женщин - $69(39,7 \%)$. Возраст оперированных

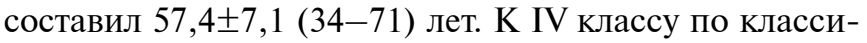
фикации NYHA относились $115(66,1 \%)$ пациентов и к III классу - $59(33,9 \%)$.

Согласно эхокардиографии, у всех оперированных имело место хроническое постстенотическое расширение восходящей аорты $(47,2 \pm 1,2$ мм) без признаков расслоения и отсутствовали данные относительно кистомедионекроза или синдрома Марфана. Величина синусов Вальсальвы при эхокардиографическом исследовании составила $36,3 \pm 2,8$ мм. Кальциноз аортального клапана +3 отмечен у $165(96,7 \%)$ пациентов.

Все операции выполнялись в условиях искусственного кровообращения и умеренной гипотермии $\left(28-34^{\circ} \mathrm{C}\right)$. Защита миокарда осуществлялась в условиях фармакохолодовой кардиоплегии. В последние годы предпочтение отдаем комбинированной антеретроградной кардиоплегии раствором Кустодиол в сочетании с наружным охлаждением сердца. Доступ к аортальному клапану осуществлялся посредством поперечного (169 пациента) и продольного (5 пациентов) разрезов аорты. При размерах восходящей аорты около 5 см выполняли экономную краевую резекцию ВА по линии разреза (141 - 85,7\% пациентов).

У всех пациентов выполнялось укрепление синусов Вальсальвы в зоне некоронарной створки, где воздействие ударной волны из левого желудочка было наибольшим, и частично в зонах левой и правой коронарной створок посредством монотефлоновой полоски шириной 20 мм и длиной около 50 мм. При этой методике фиксацию аортального протеза в проекции левой и правой коронарных створок осуществляли отдельными П-образными швами в субаннулярную позицию, а в зоне некоронарной створки осуществляли посредством вкалывания в основание фиброзного кольца снаружи П-образного шва (пролен 2-0) и далее на манжетку протеза (71 пациент). 
После завязывания около 6-7 швов, проведенных через монотефлоновую полоску, каждый шов последовательно выкалывался через синус Вальсальвы наружу на прежнюю монотефлоновую полоску, но несколько выше прежнего уровня фиксации.

Был также применен модифицированный вариант фиксации. Вначале осуществлялось проведение шва в зоне некоронарного синуса через манжетку протеза, затем через фиброзное кольцо, и далее проводилось частичное сбаривание синуса Вальсальвы. В случае его расширения проводился шов на наружную стенку аорты - на монотефлон, с последующей его фиксацией (103 пациента).

Данная методика более удобна и, кроме того, позволяет экономить около 10-12 минут времени аноксии по сравнению с первоначальной методикой.

Укрепив зону некоронарного синуса Вальсальвы, проводили фиксацию проведенных 5-6 швов к проксимальному концу тесемки (нейлон JohnsonJohnson шириной 10 мм), которым затем окутывали восходящую аорту. Обведя тесемку над устьем и
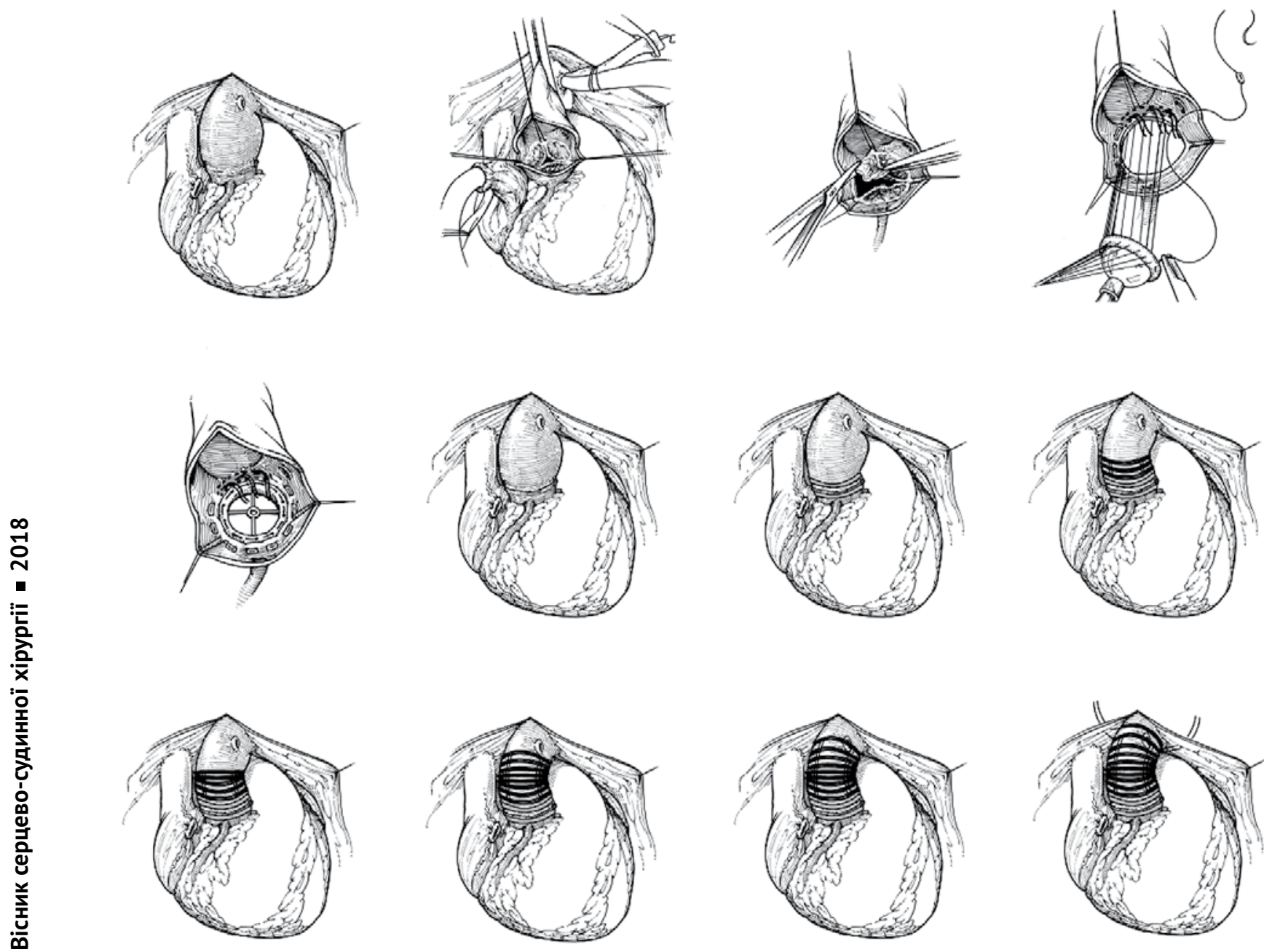

позади левой коронарной артерии, ее дополнительно иммобилизовали к ВА в проекции стыка левой и правой коронарных створок П-образным швом, выведенным изнутри аорты на тефлоновой прокладке. Данная фиксация позволила точно определить направление тесемки вдоль заднего верхнего края синуса Вальсальвы левой коронарной створки, исключив ее смещение и влияние на устье левой коронарной артерии.

Завершался первый этап укрепления синусов Вальсальвы фиксацией под натяжением тесемки к стыку правой и некоронарной створок, т. е. к исходной позиции, откуда началась фиксация тесемки (завершенный кольцевой первый оборот). Последующие туры (7-9 раз) обертывания восходящей аорты под натяжением (бандажирование) уже выполнялись на этапе согревания пациента с фиксацией туров между собой по линиям как ближе к легочной артерии, так и альтернативно - ближе к краю поперечного синуса. Данная технология обозначена термином wrapping tape operation (WTO) (рис. 1).
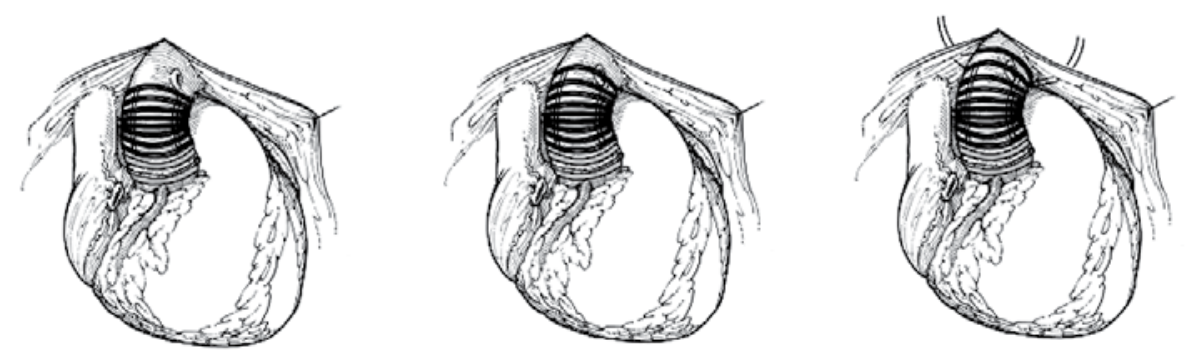

Рис. 1. Схема простого тесемочного окутывания восходящей аорты 
Попов В. В. / Тесемочное окутывание восходящей аорты при ее постстенотическом расширении и коррекции...

За период 2014-2016 гг. у 27 пациентов была применена модификация wrapping tape operation II , при которой при расширении синусов Вальсальвы более 4,0 см применено укрепление зоны синусов на стыке левой и правой коронарных артерий. Для этого два шва на стыке левой и правой коронарных створок были проведены с манжетки протеза наружу и далее фиксировались на тефлон и полоску аутоперикарда раз мером $3 \times 3$ см, а в дальнейшем фиксировались к бандажной тесемке. Это позволило укрепить синусы Вальсальвы с этой стороны. По эхокардиографии - изменение размера синусов Вальсальвы: до операции 41,2 $\pm 0,5$ мм, а на момент выписки $35,2 \pm 0,4$ мм.

Имплантированы в аортальную позицию протезы двухстворчатые (Carbomedics, St. Jude Medical, On-X, Edwards-Mira) $(n=172)$ и монодисковые $(n=2)$. Время

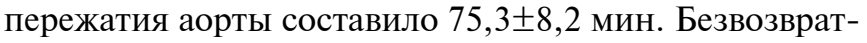
ная кровопотеря составила в пределах 400,0 мл, что позволило полностью исключить применение донорской крови и ее компонентов на операции и в послеоперационный период у $47(27,0 \%)$ пациентов. Не было отмечено случаев кровотечения при манипуляциях на аорте либо специфических осложнений, связанных с реконструкцией некоронарного синуса Вальсальвы и процедурой окутывания восходящей аорты.

Результаты и их обсуждение. Среди 174 последовательно оперированных по данной методике пациентов на госпитальном этапе умер один (госпитальная летальность - 0,6\%). Причина - полиорганная (дыхательная) недостаточность на фоне выраженного кифосколиоза. Доза инотропной поддержки (добутамин) у всех пациентов была в пределах 3-4 мкрг/кг/мин. в течение 48 ч. после операции. Пациенты экстубированы в течение $7,1 \pm 1,3$ часов после окончания операции. После пребывания в отделении интенсивной терапии в пределах 48-72 часов без осложнений пациенты были выписаны для последующей реабилитации на $10,5 \pm 3,4$ сутки после операции. При эхокардиографическом исследовании размер восходящей аорты составил до операции $4725 \pm 1,2$ мм, на момент выписки $39,7 \pm 1,4$ мм, в отдаленный период $-40,2 \pm 0,5$ мм, а диаметр синуса Вальсальвы до операции составлял $41,2 \pm 0,5$ мм, на момент выписки $-35,2 \pm 0,4$ мм, а в отдаленный период $-36,8 \pm 0,8$ мм.

У 159 (91,9\% от числа выписавшихся) пациентов в сроки наблюдения после операции $8,1 \pm 1,4$ лет не было отмечено специфических осложнений, связанных с реконструкцией некоронарного синуса Вальсальвы и восходящей аорты. Хорошие и удовлетворительные результаты отмечены у $135(84,9 \%)$ пациентов. Умерло $4(4,1 \%)$ пациента по причинам, не связанным с коррекцией пороков. Реоперация по замене аортального протеза по поводу инфекционного эндокардита была успешно выполнена через 8 лет. Состояние стенки аорты в зоне наложения тесемки удовлетворительное.

Обсуждение. Коррекция постстенотического расширения восходящей аорты в случае протезировании аортального клапана относится к важному разделу в хирургии приобретенной патологии [1-5]. Наряду с операциями протезирования восходящей аорты (Wheat, Benthall, "Button"-technice) нашли воплощение и операции экзопротезирования восходящей аорты типа Робичека, что позволило в ряде случаев радикально корригировать патологию при минимальном риске вмешательства, хороших отдаленных результатах, минимальном числе осложнений, не связанных с сосудистым протезным эндокардитом и несостоятельностью при этом анастомозов [1-3]. Наряду с этим поиск оптимального варианта экзопротезирования не прекращается с целью снижения риска госпитальной летальности и улучшения отдаленных результатов [4-7].

На основании полученного клинического опыта нам представляется целесообразным рекомендовать оригинальную методику комплексного тесемочного окутывания корня и ВА при их расширении (4055 мм) в сочетании с ПАК при умеренном аневризматическом расширении восходящей аорты. Методика позволяет улучшить морфометрию ВА, синуса Вальсальвы за счет его некоронарной составляющей и равным образом провести профилактику аневризмообразования в зоне восходящей аорты в отдаленные сроки. Методика малотравматичная, недорогая, позволяет достаточно оптимально нормализовать размеры ВА сразу на госпитальном этапе и удерживать их стабильными в среднесрочном периоде. По мере накопления клинического опыта можно более точно оценить надежность методики в отдаленный период наблюдения (15 лет и более).

\section{Литература}

1. Biomechanical properties of the thoracic aneurysmal wall: differences between bicuspid aortic valve and tricuspid aortic valve patient / Forselli C., Bjork Y. M., Eriksson P. et al. // Ann Thorac Surg. - 2014. - Vol. 98. - P. 65-71.

2. The ascending aorta with bicuspid aortic valve: a phenotypic classification with potential prognostic classification with potential prognostic significance / Corte D., Bancone C., Dialetto G. et al. // Eur. J. Cardiothorac Surg. - 2014. Vol. 46. - P. 240-247.

3. Comparative history of aortic dilatation associated with dileaflet versus trileaflet aortic valves / Heng E., Stone J., Kim J. et al. // Ann. Thorac. Surg. - 2015: - Vol. 100, N 6. - P. 2095-2101.

4. Лазоришинец В. В., Попов В. В., Большак А. А. Экзопротезирование восходящей аорты при ее постстенотическом расширении и коррекции аортального стеноза // Кардиология в Беларуси. - 2016. - Т. 8, № 3. - C. 15-20. 
5. Попов В. В., Большак А. А. Тесемочный бандаж восходящей аорты при ее постстенотическом расширении // Вісник серцево-судинної хірургії. - Вип. 22. Київ, 2014. - С. 248-252.

6. Managemant of dilated ascending aorta during aortic valve replacement alone versus aorta wrapping versus aorta replacement / Lee S., Kim J., Kim D. et al. // J. Thorac Cardiovasc Surg. - 2013. - Vol. 146. - P. 802-809.

7. Coxiela burnetti endocarditis and aortic vascular graft infection / Maor Y., Sternik L., Orlov B. et al. // Ann Thorac Surg. - 2016. - Vol. 101. - P. 141-145.

\title{
Wrapping tape operation for poststenotic aneurysm of ascending aorta during correction of aortic stenoses
}

\author{
Popov V., Bolshak O., Spysarenko S. P., Malysheva T. A., Lazorishinetz V.
}

National M. M. Amosov Institute of Cardiovascular Surgery National Academy of Medical Sciences of Ukraine (Kyiv)

Purpose - to determine possibilities of correction of poststenotic aneurysm of ascending aorta (PAAA) by WTO.

During 2005-2017 yy 174 patients (pts) with aortic stenoses (AS) and PAAA were operated in Institute. The following operation was performed: aortic valve replacement (AVR) + wrapping tape operaton (WTO) of AA. In all cases after AVR nylon tape (diamener $1 \mathrm{~cm}$ ) was wrapping of AA by 5-9 tours and fixation between them and in proximal and distal part of AA. Hospital mortality was $0,6 \%$. Echo examination of diameter of AA $(\mathrm{mm})$ : preoperative $47,5 \pm 1,6$, postoperative $39,4 \pm 1,3$, remote period $40,2 \pm 1,8$. On the basis of clinical experience we recommend the expedient method of WTO for PAAA (diameter of AA till $5,5 \mathrm{~cm}$ ) during AVR without prostheses of AA.

Key words: poststenotic aneurysm of ascending aorta, wrapping tape operation, $C P B$, aortic valve replacement.

\section{Смужний бандаж висхідної аорти при її постстенотичному розширенні та корекції аортального стенозу}

\author{
Попов В. В., Большак О.О., Списаренко С.П., Малишева Т.А., Лазоришинець В. В. \\ ДУ «Національний інститут серцево-судинної хірургії імені М. М. Амосова НАМН» (Київ)
}

Мета роботи - вивчити можливості оригінальної методики хірургічної корекції аневризм висхідної аорти (АВА) при протезуванні аортального клапана (ПАК).

В Інституті з 01 січня 2005 р. до 01 січня 2017 р. з приводу аортального стенозу, АВА (до 5,5 см) протезування аортального клапана виконано у 174 пацієнтів у поєднанні з тасьмовим обгортанням висхідної аорти. Вік оперованих склав 57,4 7,1 (34-71) років. До IV класу за класифікацією NYHА належали $115(66,1 \%)$ пацієнтів, до III класу $-59(33,9 \%)$.

Госпітальна летальність склала $0,6 \%$. При ехокардіографічному дослідженні розмір висхідної аорти склав до

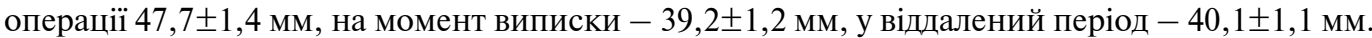

На підставі отриманого клінічного досвіду видається доцільним рекомендувати оригінальну методику смужного обгортання ВА від ії основи при її розширенні (45-55 см) у поєднанні з ПАК при постстенотичному розширенні висхідної аорти.

Ключові слова: розширення висхідної аорти, смужне обгортання висхідної аорти, штучний кровообіг. 